THE TYNDALE BIBLICAL ARCHAEOLOGY LECTURE, 1982

\title{
UGARIT, CANAAN, AND ISRAEL
}

By Peter C. Craigie

The purpose of this paper is to explore the relationship between the old Testament and one part of its ancient environment, namely Syria-Palestine, or the Eastern Mediterranean seaboard. To be more precise, the basic interest of the paper is in the discipline that is now commonly called Hebrew-Ugaritic studies, but because that discipline is fraught with a variety of theoretical difficulties, a third element is introduced, namely Canaan. In theory, one might suppose that the general difficulties involved in comparative Hebrew-Ugaritic studies would be reduced by the introduction of Canaan into the equation.

At the outset, it may be noted that the three terms in the title are not precisely the same in nature. (i) Ugarit refers to both a city and a kingdom; it designates a small nation state, located on the northeastern coast of the Mediterranean, that came to an end early in the 12 th century B.C. (ii) Canaan, on the other hand, does not refer to a single unitary state; it refers rather to a geographical area occupied over time by a variety of different states, located on the southeastern coast of the Mediterranean. Chronologically, the term Canaan continues in use after the demise of Ugarit. (iii) Israel designates a nation state, and before that, a people. ${ }^{2}$ Geographically, it is located in Canaan; chronologically, it comes into existence. as a state after the demise of Ugarit.

From this brief description of the terms, a part of the problem under consideration is immediately evident. A comparison of Ugarit and Israel involves the comparison of two states, and hence two national

1. On the use of Canaan, see further R. de Vaux, 'Le pays de Canaan,' JAOS 88 (1968) 23-30.

2. I shall use the term Israel in a broad sense, to incorporate both the United Kingdom and the subsequent states of Judah and Israel. 
cultures and all their component parts. On the other hand, the one kingdom ceased to exist before the other came into national existence, and the one was located on the northern Mediterranean seaboard (near the East Semitic and Hittite civilizations) whereas the other was situated on the southern Mediterranean seaboard (adjacent to the great Egyptian Empire). Such divergencies of chronology, geography, and context comprise the difficulties of comparison, and in the attempt to resolve such difficulties, resort may be made to Canaan.

A common assumption in the introduction of Canaan to the area of comparative studies is that it may form a kind of cultural bridge between the two poles, providing the missing link and overcoming the difficulties. The assumption has become so deep-sedted that it is rarely questioned. Thus Ugaritic myths and legends are commonly labelled Canaanite myths and legends, to use the most obvious example. 3 While in the broadest terms such usage may be acceptable, it may nevertheless veil some of the fundamental issues. Can Ugaritic items be called Canaanite? Are Ugaritic literature and religion actually representative of Canaanite literature and religion? Conversely, is the culture of Canaan, as it is known from a variety of sources, typical of that of the ancient Kingdom of Ugarit? Some clear understanding of the answers to these questions must be provided, (a) if Canaan is to function as a bridge in comparative Hebrew-Ugaritic studies, and (b) if the problems of chronology and geography in comparative Hebrew-Ugaritic studies are to be overcome. Before too easy an acceptance is granted to the equation of all things Ugaritic with Canaanite, the very least that should be noted is that the Ugaritic texts

3. Such terminology may be seen in the titles of books containing the Ugaritic texts in translation, from G. R. Driver's Canaanite Myths and Legends (Edinburgh: Clark, 1956), to G. del Olmo Lete, Mitos y Leyendas de Canaan segun la tradicion de ugarit (Madrid: Cristiandad, 1981). 
themselves clearly distinguish between Ugarit and Canaan. ${ }^{4}$ The distinction does not really clarify the issues one way or the other, for Canaan, as employed in the Ugaritic texts, may designate a slightly different territory or region than does the same term in e.g. Biblical or Amarna texts. The self-awareness of the Ugaritic texts, however, does indicate the need for caution with respect to such expressions as 'Canaanite myths and legends.' Such usage may be analogous to designating the poetry of Robert Burns as English poetry.

It is the purpose of the paper, then, to explore the relationships between the three points of the triangle (Ugarit, Canaan, and Israel), and thus to clarify all that is involved in the burgeoning field of HebrewUgaritic studies. And the latter purpose, in turn, is important precisely because Ugaritic studies have had, for better or for worse, enormous impact on OT studies during the last five decades.' That there are striking parallels between the Bible and Ugarit is beyond question, but that many of the proposed parallels have real existence only in the heads of their inventors is also evident. Yet how does one distinguish between the real and the illusory? Only by the use of as controlled a method of comparison as possible, and in the last resort, this paper is dedicated to contributing something to the issue of control in comparative studies.

The subject is a vast one, and inevitably there must

4. A Ugaritic text, KTU 4.96 .7 (= CTA 91/UT 311) refers to 'Jael the Canaanite' $\left(y^{\prime} 1 . k n\right.$ 'ny), indicating a foreigner. 'An Akkadian text, RS.20.182. B 5-6 (Ugaritica V, 111-14), makes an explicit distinction between the 'people of Ugarit' and the 'people of Canaan.' On the distinction between Ugarit and Canaan in the Amarna letters, see A. F. Rainey, 'The Kingdom of Ugarit,' BA 28 (1965) 102-25.

5. For a survey of this question, see P. C. Craigie, 'Ugarit and the Bible: Progress and Regress in 50 Years of Literary Study,' in G. D. Young (ed.), Ugarit in Retrospect. 50 Years of Ugarit and Ugaritic (Winona Lake: Eisenbrauns, 1981) 99-111. 
be a degree of selectivity in the approach to the problem. ${ }^{6}$ I shall present first a variety of general considerations pertaining to the topic, and then shall focus in more detail on a number of specific topics which may illuminate the difficulties and point toward solutions.

\section{GENERAL CONSIDERATIONS}

At the outset, it must be noted that there are both problems and possibilities in examining the interrelationships between Ugarit and Canaan in the late Bronze Age. ${ }^{3}$ That there was a variety of kinds of interrelationship of an historical nature between Ugarit and Canaan is clear; the extent to which Ugaritic culture was typical of, or representative of, that uf Canaan is far from clear.

The most obvious example of interrelationship between Ugarit and Canaan is to be found in the matter of trade. Ugarit, though a relatively small kingdom, was nevertheless a major trading nation in the world of the Eastern Mediterranean. ${ }^{8}$ From the variety of texts found in the archives of Ugarit, it is clear that fairly extensive trade was undertaken with

6. Some of the literary problems pertaining to this issue were examined in an earlier paper and will not be elaborated in greater detail in this context, P. C. Craigie, 'The Poetry of Ugarit and Israel,' TB 22 (1971) 3-31. For a treatment of other issues not covered here, see w. Jobling, Canaan, Ugarit and the old Testament: A Study of Relationships (Ph.D., University of Sydney, 1975).

7. For a survey of some of the issues, see P. C. Craigie, 'Religious Interactions between Ugarit (Ras Shamra) and Palestine during the. Late Bronze Age,' in P. D. Francis et al. (eds.), Networks of the Past: Regional Interaction in Archaeology (Calgary: Archaeological Association of the University of Calgary, 1981) 201-06.

8. See, e.g. E. Linder, 'Ugarit: A Canaanite Thalassocracy,' in G. D. Young (ed.), Ugarit in Retrospect 31-42. 
Canaan through the sea-ports on the southeastern Mediterranean coast. 9 Trade is known to have taken place through the ports of Byblos, 10 Tyre, 11 Sidon, 12 Akko, ${ }^{13}$ and probably also Ashdod and Ashkelon.

A tablet excavated at Tell Aphek, in Israel, gives some further illumination of trading links between Ugarit and Canaan. ${ }^{14}$ The letter was sent (in the mid-13th century B.C.) from an Ugaritian official, Takuhlina, to an Egyptian official, Haya, who was apparently stationed somewhere in Canaan, though the precise location of his residence is not known. The commercial substance of the letter is indicative of the regular mercantile interaction between Ugarit and Canaan (the letter probably reached Aphek via a coastal port, either Jaffa or one of the ports listed above). Thus the discovery of the tablet at Tell Aphek adds to the general information about trade and related matters provided by the archives of Ugarit.

To this information may be added the references to Ugarit in various letters from the archives of Tell el-Amarna. ${ }^{15}$ Though the evidence of the Amarna texts is indirect, they establish nevertheless that

9. See M. Heltzer, Goods, Prices, and the Organization of Trade in Ugarit (Wiesbaden: Reichert, 1978) 151-52.

10. $P R U$ VI, 136 (RS.19.28).

11. KTU 2.38 (PRU V, 59): reference is made to a Ugaritic ship docked in the port of Tyre; KTU 2.40 (PRU V, 63).

12. $P R U$ VI, 81.4 (RS.19.182.4).

13. $P R U$ V, 59 .

14. D. I. Owen, 'Ugarit, Canaan and Egypt,' in G. D. Young (ed.), Ugarit in Retrospect 49-53.

15. See, e.g., EA 151.49-69. I am indebted to Shlomo Izre'el, Tel Aviv University, for his assistance with respect to the Amarna letters. 
Ugarit was well-known in both Egypt ${ }^{16}$ and Canaan. In summary, approximately five letters in the archives appear to have been sent to Egypt from Ugarit (EA 45-49), 17 thus providing some information on the historical interconnections between the two nations. ${ }^{18}$ In addition, explicit references to Ugarit in Amarna letters sent from Tyre (EA 151:55) and Byblos (EA 98:9; 89:51; 126:6) establish the coastal interconnections between Ugarit, Canaan, and Egypt.

The historical and mercantile interconnections between Ugarit and Canaan are supplemented to a limited extent by various kinds of archaeological data indicating a commonality of culture. Thus (as was noted in a recent Tyndale Lecture), both the architecture and location of the Ras Shamra temples have certain similarities to temples excavated at Hazor, Megiddo, and Shechem, which might also be indicative of a commonality of religion. 19 (It should be noted, however, that the temples of both Ugarit and Canaan differ in style from Solomon's temple, implying that even if Ugarit may be representative of Canaan in certain matters, both may nevertheless be quite different from Israel, which at this point has closer similarities to the temple architecture of northeastern Syria.)

While similarities of temples may be indicative of the commonality of religion between Ugarit and Canaan, extreme caution must be exercised at this point. Thus, the cult of Baal appears to have functioned in Syria, Canaan, and even in Egypt. 20 But one cannot

16. R. Giveon, 'Some Egyptological Considerations Concerning Ugarit,' in G. D. Young (ed.), Ugarit in Retrospect 55-58.

17. W. F. Albright, 'An Unrecognized Amarna Letter from Ugarit,' BASOR 95 (1944) 30-33.

18. M. Liverani, Storia di Ugarit nell'eta degli Archivi Politici (Studi Semitici 6; Rome: University of Rome, 1962) 23-30.

19. C. J. Davey, 'Temples of the Levant and the Buildings of Solomon,' TB 31 (1980) 107-46.

20. J. Gray, 'Canaanite Mythology and Hebrew Tradition,' TGUOS 14 (1953) 47-57. 
assume on this basis that the cult of Baal was in all places the same; indeed, it may be safer to refer to the cults of various baalim. To give an example, one of the two temples in Ras Shamra has been identified (though with somewhat fragile evidence) as a temple of Baal. If the identification is correct, it is particularly interesting to note the manner in which several stone anchors have been physically incorporated into the temple structure. ${ }^{2}$ If it may be surmised that the presence of these stone anchors in the temple has religious significance, then presumably we may see the way in which Ugarit's maritime location has influenced the local cult of Baal. On the other hand, one would assume that the cult of Baal in most Canaanite centres was typified by the more traditional agricultural emphases. And whether the mythology of Baal, as it is known from the Ugaritic texts, was typical of Ugarit, or Canaan, or neither, cannot be known with certainty; the commonality of that mythology with Mesopotamian patterns ${ }^{22}$ may indicate either foreign or universal themes.

The necessity of caution, in the matter of the religion of Baal, is implied further by the general character of other archaeological data. Rudolph Dornemann has warned of the dangers of taking Syria and Palestine together, as if they formed a single cultural unit. ${ }^{23}$ He notes that in the matter of pottery and other artefacts, there are such differences between the northern and southern regions, that terms such as syriaPalestine can be used only with extreme caution.

Care is needed especially in the matter of the languages and dialects of the two regions. The question of the linguistic classification of Ugaritic,

21. H. Frost, 'The Stone Anchors of Ugarit,' Ugaritica 6 (1969) 235-43.

22. T. Jacobsen, 'The Battle between Marduk and Tiamat,' JAOS 88 (1968) 104-08.

23. R. H. Dornemann, 'The Excavations at Ras Shamra,' in G. D. Young (ed.), Ugarit in Retrospect 59-67. 
Hebrew, and the Canaanite dialects remains under dispute, ${ }^{24}$ but throughout the history of HebrewUgaritic studies, a very close relationship between Hebrew and Ugaritic has always been presupposed. To some extent, the supposition has been warranted. There are indeed striking similarities between the languages and they share a high proportion of common lexical stock. But in this comparison, differences may be far more significant than similarities. To use a modern example, Arabic is spoken in Latakia, Damascus, and Bethlehem. The degree of similarity between the forms of Arabic used in these three localities is overwhelming, yet an awareness of the similarity may hide the particular significance of the differences. The Arabic of Latakia has several grammatical and lexical peculiarities that distinguish it from the language spoken further south; ${ }^{25}$ here, as in many parts of the world, there is a peculiar conservatism in the regional variations of language. And to pass from the analogy directly back into the subject matter, it is fascinating to note how in some recent studies, undertaken by those with a knowledge of modern Latakian Arabic, similarities between the modern regional peculiarities and the ancient Ugaritic language are being identified. ${ }^{26}$ This phenomenon of a large degree of cultural commonality in a geographical area, with distinctive peculiarities in its various regions, is not limited to language; it extends also to such matters as literature and

24. See Craigie, TB 22 (1971) 5-7.

25. I owe this observation to M. Gabriel Saadé, of Latakia, Syria.

26. L. Badre, P. Bordreuil, J. Mudarres, L. 'Ajjan, R. Vitale, 'Notes Ougaritiques I. Keret,' Syria 53 (1976) 95-125 (for examples of similarities between Ugaritic and the modern regional dialect, see pp. $105,116,125)$. For a quite different approach to the subject, see A. F. Rainey, $B A 28$ (1965) 102-25, who notes the differences between the Ugaritic and Canaanite dialects by reference to the glosses in the Amarna letters; he considers Ugaritic and Hebrew to be different Semitic languages. 
religion. To return to the modern analogy: one of the principal causes of tension within modern Syria is to be found in the fact that the religion and culture (the 'Alouite' tradition) of Mediterranean Syria is very different from that of the rest of Syria, causing certain difficulties between different power groups within the nation. One may perhaps assume that in the ancient world, when those same territories were not even united within a single national boundary, the differences and peculiarities were at least as great.

These introductory and general perspectives set the stage for comparative studies. Ugarit had direct links of a mercantile nature with Canaan; it also shared some general linguistic and cultural characteristics with Canaan. But there were also significant differences pertinent to comparative studies, and now we must examine a few specific points in a little more detail, in an attempt to establish some fairly firm horizons within which Hebrew-Ugaritic studies may be conducted.

\section{UGARITIC TEXTS FROM LOCATIONS OTHER THAN RAS SHAMRA}

One collection of data that might be used as part of an argument for the representative character of Ugaritic language and literature is the collection of texts in the Ugaritic script that have been discovered at a variety of sites in Syria and Palestine beyond Ras Shamra. Given the wide dispersal of the Ugaritic-type cuneiform alphabetic script, it might be argued, is it not also probable that the culture and civilization known in the Kingdom of Ugarit were also widely dispersed throughout the so-called Syro-Palestinian region?

Texts in alphabetic cuneiform have been recovered from a total of ten sites in Syria and Palestine and can be gathered conveniently into two groups. Group I consists of texts from those sites which were, in all probability, within the territory belonging to the Kingdom of Ugarit:

(a) Ras Shamra (Ugarit itself); (b) Minet el-Beida (the neighbouring port town, Ma'badu?); (c) Ras Ibn Hani, a few kilometres to the southwest of Ras Shamra; (d) and Tell Sukas, located on the coast further south (Shuksi). Group II consists of texts from a variety of other sites, places which were not part of Ugarit's territory, nor 
controlled by it. In this group, there are six sites: (a) Tell Nebi Mend (east of Ugarit, on the R. Orontes); (b) Tell Taanach; (c) Mt. Tabor; (d) Kamid el-Loz (Kumidi); (e) Beth Shemesh; (f) Sarepta. These sites are widely distributed throughout Syria and Palestine, from Tell Nebi Mend in the north of Syria to Beth Shemesh, Tell Taanach and Mt. Tabor in Palestine; Sarepta is on the Mediterranean coast (between Tyre and Sidon), while Kamid el-Loz is inland (in southern

Lebanon). In summary, the Ugaritic script appears to have been in use at a variety of locations within the territories designated nowadays as Syria, Lebanon, and Israel. ${ }^{7}$ For the purposes of the issue under discussion, it is the inscriptions in Group II that are of particular significance and which must be examined.

It must be stated at once that the substance of these texts, while not insignificant, is of little help in determining the issue one way or the other. The Tell Sukas inscription in Group $I$, and all the inscriptions in Group II, are extremely short; they contain little that could be used for determining any argument with respect to religion and culture, and even taken cumulatively, they contain insufficient data to be

27. Texts from Ras Shamra and Minet el-Beida are published in KTU. The other key texts referred to in this paragraph are as follows: (a) Tell Sukas = TS 4001 (KTU 4.766); on the relation of the site to the Kingdom of Ugarit, see M. C. Astour, 'The Kingdom of Siyanna-UŠnatu,' UF 11 (1979) 13-28. (b) Tell Nebi Mend = TNM 022; A. R. Millard, 'A Text in a Shorter Cuneiform Alphabet from Tell Nebi Mend,' UF 8 (1979) 459-60. (c) Tell Taanach = TT 433 (KTU 4.767); M. Dietrich, O. Loretz, J. Sanmartín, 'ZU TT 433,' UF 6 (1974) 469-70 (with bibliography of earlier studies). (d) Mt. Tabor = KTU 6.1 (UT 501). $\quad$ (e) Kamid el-Loz = KL 67.428 (KTU 6.2); G. Wilhelm, 'Eine Krughenkelinschrift in alphabetischer Keilschrift,' UF 5 (1973) 284-85. (f) Beth Shemesh = KTU 8.1 (UT 500). (g) Sarepta = SAR 3102; D. Owen in J. B. Pritchard (ed.), Sarepta. A Preliminary Report on the Iron Age (Philadelphia: University Museum, 1975) 102-04; E. L. Greenstein, 'A Phoenician Inscription in Ugaritic Script,' JANES 8 (1976) 49-57; P. Bordreuil, 'L'inscription de Sarafand en cunéiformes alphabétique,' UF 11 (1979) 63-67. 
decisive. Furthermore, some are extremely short and general (the principal Kamid el-Loz inscription simply reads: $1 \mathrm{rb}$ ), whereas others are essentially unintelligible (e.g., the Beth Shemesh inscription).

As for the form of the alphabet used in these inscriptions, there is a little more data to work on. 28 In general terms, there. was a long and a short form of the cuneiform alphabet. The long alphabet (containing 30 symbols) was the regular alphabet in use at Ras Shamra, Minet el-Beida, and Ras Ibn Hani; it was also employed in the Tell sukas inscription. The short, or reduced alphabet, is the form used in the inscriptions from Sarepta, Kamid el-Loz, Beth Shemesh, Tell Taanach, and Mt. Tabor. Only three texts in the short alphabet were found in Ugarit as such, ${ }^{29}$ and a variant form of the short alphabet was in use at Tell Nebi Mend. That is to say, the long form of the alphabet was the normal form used within the territory belonging to the Kingdom of Ugarit; in all the southern (or 'Palestinian') sites, the short alphabet was used. To oversimplify, and with awareness of the limitations imposed by the fragmentary nature of the evidence, the cuneiform alphabet most commonly employed in Ugarit (Syria) is not representative of that employed in Palestine. While a variety of reasons for this variation may be proposed, ${ }^{30}$ one significant possibility is that the dialects or languages employed in the south (Canaan) were sufficiently different from the language of Ugarit as to be conveyed coherently in the shorter alphabet, with its

28. See further A. R. Millard, 'The Canaanite Linear Alphabet and its Passage to the Greeks,' Kadmos 15 (1976) 130-44; M. Dietrich, O. Loretz; and J. Sanmartín, 'Das reduzierte Keilalphabet,' UF 6 (1974) 15-18; Y. Priebatsch, ' $S$ und $T$ in Ugarit und das Amoritische. Ein Beitrag zur Geschichte des ABC,' UF 7 (1975) 389-94; A. R. Millard, 'The Ugaritic and Canaanite Alphabets--Some Notes,' UF 11 (1979) 613-16.

29. CTA 187 (KTU 1.77); CTA 207 (KTU 4.31); RS 22.03 (KTU 4.710).

30. E.g., the script in use in Ugarit had to function as a vehicle for other languages apart from Ugaritic, including Hurrian and Akkadian. 
fewer phonetic distinctions. In this minor point, the evidence from Ugarit does not appear to be representative of the situation in the south, or the Canaan of Biblical times.

In addition to the respective lengths of the alphabet, there is the intriguing question of the direction in which the script was written. The conventional direction within the Kingdom of Ugarit was from left-to-right, and a similar direction is employed in the inscriptions from Sarepta and Tell Taanach. The right-to-left direction was employed at Mt. Tabor, Beth Shemesh, and Tell Nebi Mend (and in the three atypical texts from Ugarit). At Kamid el-Loz, two fragmentary inscriptions were found. The published text reads from left-to-right, whereas the unpublished (and illegible) text reads from right-to-left. Here, the evidence is too mixed to be firm. The most common direction of writing in the south, or Canaan, was right-to-left ( 3 sites, only Tell Taanach being different). But perhaps the only firm conclusion that can be drawn from these data is that there was a variety of practice and that the common practice of Ugarit was not typical of what may have been the common practice of Canaan.

There is a final point to be made, of a different nature, though not without significance. It is simply that whereas (within the limits of the current evidence) the cuneiform alphabet appears to have flourished primarily in the north, the development of the linear alphabet (from which, eventually, the Hebrew alphabet was derived) appears to have taken place primarily in the south. To the evidence of the last decades may now be added the significant new evidence of the abecedary found on an ostracon at Izbet Sartah. ${ }^{31}$ The evidence again constitutes too fragmentary a foundation to form the basis

31. See particularly M. Kochabi, 'An Ostracon of the Period of the Judges from 'Izbet Șarțah,' Tel Aviv 4 (1977) 1-13; A. Demsky, 'A Proto-Canaanite Abecedary dating from the period of the Judges and its Implications for the History of the Alphabet, Tel Aviv 4 (1977) 14-27. 
of solid argument, but it would appear to support still further the general view that in matters of writing there were quite different trends and influences at work in the south (Canaan) than in the north (Ugarit/Syria). And, finally, it is clear that evidence for the dispersal of the Ugaritic script cannot be taken as evidence for the dispersal of Ugaritic language. While some inscriptions are too short to classify linguistically, that from Sarepta may with reasonable confidence be classified as a Phoenician inscription in Ugaritic script. ${ }^{32}$

\section{THE HURRIAN FACTOR}

Any comparative study of Ugarit and Israel must recognize at the outset that Ugarit cannot be identified as a unified culture or civilization. While there were, no doubt, uniquely native features, the overriding impression of the Kingdom of Ugarit is that of its cosmopolitan character. There were several languages and scripts in use, several foreign and/or ethnic . communities within the city, and varieties of architectural style indicating influences from various places beyond the coast of Syria. The ethnic communities within Ugarit are of particular interest; while some, no doubt, represented simply merchants and foreign delegations, others had become regular citizens of the city. In addition to the native (Semitic speaking) Ugaritians, the Hurrians seem to have formed a significant sector of Ugarit's population, as reflected both in personal names and in a variety of texts written in the Hurrian language. In this respect, Ugarit was little different from other contemporary cities of the Late Bronze Age, in most of which there were significant Hurrian communities (e.g., Nuzi, Alalakh).

The Hurrians take on particular interest for a number of reasons. First, in addition to the Hurrians in Ugarit, it is known that many towns and cities in Canaan to the south also had Hurrian populations: e.g., Megiddo, Taanach, and Shechem. ${ }^{3}$ Second, the Hurrians were among

32. See E. L. Greenstein, JANES 8 (1976) 49-57.

33. C. J. Mullo. Weir, 'Nuzi,' in D. W. Thomas (ed.), Archaeology and old Testament Study (Oxford: Clarendon Press, 1967) 73-86. 
the principal intermediaries of culture and civilization throughout the Ancient Near East, and are noted as one of the channels by which the culture of Mesopotamia was transmitted to the western Semitic world. ${ }^{34}$ Third, within Ugarit itself, the Hurrians clearly had considerable influence from time to time; some kings in Ugarit had Hurrian names, probably reflecting inter-marriage between the royal family and Hurrian families. ${ }^{35}$ Finally, as the third point suggests, there remains the possibility that the culture that is conventionally labelled 'Ugaritic' may already have been profoundly influenced by the Hurrians in some fashion at an early point in Ugarit's history. These are the elements of the 'Hurrian factor' that invite further exploration with respect to the comparative study of Ugarit, Canaan, and Israel.

(a) We begin by noting the manner in which the commonality of Hurrian populations may suggest interconnections between Ugarit and Canaan. In a Hurrian text from Ras Shamra, excavated in the so-called 'priest-magician's' house, there is a reference to El Berith, God of Covenant. ${ }^{36}$ The expression is used in a context of other gods who familiarly witnessed the formation of covenants or treaties, but in addition, it should be noted that the religion of the Hurrians was related (in a syncretistic fashion) to that of the Indo-Aryans. The Hurrian 'God of Covenant', in other words, may be related. to the general concept of a covenant god, known from the Hittite Empire and eastwards as far as the Indian Vedic religion. ${ }^{37}$

The only other non-Hebrew attestation of El Berith is to be found in Shechem, where it is used of a building of some

34. W. F. Albright, The Archaeology of Palestine (Penguin Books: Harmondsworth, 1960) 184.

35. See further, on Ugaritic Kings, A. F. Rainey, 'The Kingdom of Ugarit,' $B A 28$ (1965) 102-25; K. A. Kitchen, 'The King List of Ugarit,' UF 9 (1977) 131-42.

36. RS 24.278.14-15 (Ugaritica V, 515); the text was excavated during the 24th campaign (1961). On the excavations, see Ugaritica VI, 45-119. On the translation of the Semitic phrase el brt in the Hurrian text, see P. C. Craigie, 'El brt. El dn,' UF 5 (1973) 278-79.

37. Craigie, UF 5 (1973) 279. On the Indo-Aryan links of the Hurrians, see also Albright, Yahweh and the Gods of Canaan (London: Athlone Press, 1968) 103. 
kind, apparently a fortress (Jdg. 9:46). It is reasonably clear from the biblical sources and from the study of the names of various Shechemites, that the city of Shechem had a considerable Hurrian population; indeed, Speiser has argued that shechem was primarily a Hurrian settlement. ${ }^{38}$ Thus, of the two expressions used in Judges 8-9, namely baal berith and el berith, the latter is probably the proper name of the place/deity, whereas the expression baal berith designates the name of the place/deity in the local Shechemite-Canaanite dialect (baal in the sense 'lord').

(b) We may go a step further and note that in the associations of the Hebrews with Shechem, from patriarchal times to the period of the settlement, there are frequent references to Hurrians (or 'Horites,' or 'Hivites') and to the peculiar relationship between the Hebrews and these people. ${ }^{39}$ The Hurrians were not, for the most part, enemies of the Hebrews, nor are they listed among those conquered by them. Thus, the parallel between Ugarit and Shechem, in the matter of EI Berith, and the parallel between both Ugarit and Shechem, on the one hand, and the religion of the Hebrews on the other, may be more than coincidental. While it is clear that the religion of El-berith in Shechem, at the time of the settlement, had become debased, it is nevertheless possible that it retained the remnants of a more ancient religious tradition with certain similiarities to that of the Hebrews.

(c) The example of Shechem raises the question as to whether further Hebrew-Ugaritic parallels may be explained in part in terms of the 'Hurrian factor.' The following possibilities are worth further exploration. (i) A number of parallels have been proposed from time to time between the $K R T$ legend and the OT; apart from the

38. E. A. Speiser, 'Hurrians,' $I D B 2,664-66$. On the 'Hivites' as Hurrians, and their presence in Shechem, see R. North, 'The Hivites,' Bib 54 (1973) 43-62.

39. Gn. 33:15 - 34:31; Hamor and his family were apparently Hurrian. Jos. 9:7 (LXX) refers to a covenant between Joshua and Hurrians. Likewise, Abimelech appears to have been Hurrian on his mother's side of the family (Jdg. 9:1-6). 
detailed examinations of literary and philological matters, attention has been drawn. to the overall sense of similarity that $K R T$ has to the biblical patriarchal narratives. But, as several scholars have noted, the KRT legend contains a number of Hurrian (and Indo-Aryan) elements, both with respect to names of persons, ${ }^{40}$ to cultural matters, ${ }^{41}$ and perhaps also to geographical references. ${ }^{42}$ while the KRT legend in its current form is clearly Semitic and Ugaritic, its possible Hurrian antecedents are difficult to deny, and some of the parallels between KRT and the OT may not be, in the strict sense, Hebrew-Ugaritic parallels, but rather older Hebrew-Hurrian parallels. (ii) A second, minor point worthy of reflection is the possible linguistic link between Hebrew and Hurrian. Although Hurrian is not a Semitic language, Speiser has noted that the Hebrew variation in the pronunciation of the BGDKPT letters, while generally non-Semitic, is nevertheless indigenous to Hurrian. ${ }^{3}$ The point is a fragile one, given the nature of the evidence, but it may suggest further Hebrew-Hurrian interconnection at some point in history. (iii) Finally, there is the question of the identity of the Jebusites in Jerusalem. At least two Jebusite rulers had Hurrian names (Abdihepa, referred to in the Amarna letters, and Araunah, 44 2 Samuel 24:24), suggesting a continuing Hurrian element in

40. Albright, Yahweh and the Gods of Canaan 103. J. Gray, The Krt Text in the Literature of Ras Shamra (Leiden: Brill, 19642).

41. N. Wyatt, 'Some Observations on the Idea of History among the West Semitic Peoples,' UF 11 (1979) 827-28.

42. M. C. Astour, 'A North Mesopotamian Locale of the Keret Epic?,' UF 5 (1973) 29-40; Astour is very cautious with respect to the Hurrian links of the Epic, but by making so strong a case for the original geographical locale of the epic, the Hurrian links remain possible.

43. Speiser, IBD 2 664-66. On Hebrew-Hurrian interrelationships, see further G. Rendsburg, 'Late Biblical Hebrew and the Date of "P", JANES 12 (1980) 65-80.

44. The name Araunah has been the subject of debate. H. B. Rosen has suggested the name may be Hittite ('Arawna-Nom Hittite?, VT 5 (1955) 318-20), on the basis of arawanni, 'free'. However, a Hurrian origin (iwri) is more likely; Baumgartner, HAL 1 83; F. F. Bruce, 'Araunah,' IBD 1 93, citing H. A. Hoffner. Further evidence of Hurrians in Jerusalem may probably be found in the expression $\mathrm{EN}^{\mathrm{r}} \dot{i}$ in $E A, 286.7$, which may also be identified with Hurrian iwri ('lord'); 0 . Loretz; $; N^{r i}=$ IWRI in EA 286,' UF 6 (1974) 
the traditions of Jerusalem.

What is the cumulative effect of this evidence with respect to Hurrians in Ugarit, Canaan, and Israel? First, it is possible that many Hebrew-Ugaritic comparisons are more precisely Hebrew-Hurrian comparisons, sometimes in a direct sense, and sometimes indirectly (viz. with Hurrian data that have been modified to Ugaritic form). Second, the continuity of the Hurrian tradition in the geographical area of Canaan, long after the demise of the Kingdom of Ugarit, may suggest the vehicle of certain cultural interrelationships which are the source of comparative studies. Third, and this is a hypothetical point, the Hurrian data may suggest that we should take seriously the antiquity of the Hebrews' own traditions, especially the patriarchal traditions, for they may represent a period of potential Hebrew-Hurrian interconnection.

IV GEOGRAPHICAL PERSPECTIVES: UGARIT, GALILEE AND BASHAN

In the early days of Ugaritic studies, numerous geographical identifications were proposed in the Ugaritic texts, most of which were located in Canaan; places mentioned in the KRT legend were identified with various localities from the Negeb in the south, to Phoenicia and Galilee in the north. For the most part, these early geographical proposals have been either forgotten or withdrawn, as more light has been brought to bear on the texts, and the improbability of some of the geographical suggestions has been made evident. Nevertheless, the attraction of the early geographical hypotheses is clear; on the one hand, they appeared to provide some rationale for the evident parallels between the Ugaritic and Hebrew literature, and on the other hand, they seemed to provide some foundation for the pursuit of further comparative studies of a similar nature. Although almost all the old geographical hypotheses have now been abandoned, nevertheless they reflect to the merit of those scholars of the early decades of Ugaritic studies; if they had been right, they would at least have secured some foundation for the fundamental problem of geographical distance which should affect all comparative Hebrew-Ugaritic studies. In contemporary scholarship, although the geographical hypotheses have been abandoned for the most part, no extensive work has been undertaken to account for the difficulties implied by the physical distance separating Jerusalem from Ugarit, as logic would dictate that it might. 
The principal exception to this description of contemporary scholarship is to be found in the work of Baruch Margalit; whatever one may think of his results, he has surely identified a significant problem. In a recent study, he wrote: 45 'There is a seemingly unbridgeable gap, both in time and in space, between Jerusalem and Ugarit.... alongside a fundamental continuity in their respective literatures.' Margalit's various geographical hypotheses attempt to bridge that gap; they are in part a return to old evidence, but for the most part comprise an elaborate new set of arguments based on a variety of Ugaritic texts. His two most significant arguments might be called respectively the 'Galilean Hypothesis' and the 'Bashan Hypothesis.' Both deserve careful attention.

(i) The Galilean Hypothesis has been developed in two studies. In the first, Margalit attempted to establish the presence of Chinnereth in the $A Q H T$ text; ${ }^{46}$ in the second study, he attempted to build further upon the evidence of the first proposal. ${ }^{47}$ The second and more detailed study contains an elaborate series of arguments, somewhat speculative in nature, attempting to identify various sites and events in the AQHT story with the geographical terrain around Sea of Galilee. Indeed, the arguments are quite extraordinary for their precision in geographical location; in my judgment, all the arguments would seem quite improbable, or at least not. persuasive in themselves, were it not for the fact that all are preceded by the identification of Ugaritic knrt with Chinnereth. One does not wish to take Margalit's arguments lightly, but they seem to be like a precarious house of cards; if the knrt-card stands, the rest may stand with it, but without that sure foundation, the remainder of the argument loses its persuasiveness.

The identification knrt/Chinnereth is proposed in the first of the two studies noted above. At the outset,

45. B. Margalit, 'The Geographical setting of the $A Q H T$ Story and Its Ramifications,' in G. D. Young (ed.), Ugarit in Retrospect 131-58.

46. Margalit, 'Studia Ugaritica II: Studies in KRT and AQHT,' UF 8 (1976) 172-77.

47. See the article cited in note 45 above. 
it should be admitted that if the reading knrt can be sustained, the identification with Chinnereth is possible, though not proved. But the key question concerns the reading of the word in the text in question: CTA 19.147 (KTU 1.19.111.41). Everything depends on this single text, as the word is nowhere else employed in the Ugaritic corpus, to the best of my knowledge. What is clear at the outset is that the reading is difficult, however one resolves it; the word comes at the end of a line in column 3 of the tablet in question, but the tablet is broken at the right hand side (between columns 3 and 4 ) and has some slight surface abrasions. There are five letters following a word divider, of which the reading of two critical letters is uncertain. All editions of the texts, from CTA to KTU, note the uncertainty in the reading; Herdner renders it bknk-; her drawing would suggest bknkt, though the broken tablet may have erased part of the last letter, indicating not $/ t /$ but $/ \mathrm{n} /$. Of the authorities, by far the majority assume something like bknkn ('in a grave'); of those few who read bknrt, Driver translates the expression 'in a shroud', citing a Persian-Arabic cognate term. ${ }^{48}$

In summary, the problem is epigraphic, as Margalit recognizes; it is unlikely to be solved to everyone's satisfaction. My preference, based on Herdner's drawing, is bknkt/n, though that could well be wrong. But Margalit's solution is to attempt to resolve an epigraphic problem by resort to non-epigraphic data, and at this point his argument becomes less than totally convincing. The essence of the matter can be reduced to these basic points. (a) It would be a dangerous process to build so elaborate a hypothesis of geographical provenance on a hapax legomenon in the Ugaritic texts, even if the reading was secure. (b) It is a still more dangerous process when the hapax legomenon is an uncertain reading. Thus, while I still find Margalit's Galilean hypothesis attractive in many ways, I do not find it persuasive.

48. G. R. Driver, CML 62-63, 145 . 
(ii) The Bashan hypothesis attempts to establish links between the biblical and Ugaritic rephaim, and to locate both in the territory of Bashan in the northern Transjordan. ${ }^{49}$ Though a number of lines of argument are adduced, the key to the entire hypothesis lies in the interpretation of lines 2-3 of RS 24.252: il ytb b'ttrt il tpt $b h d r ' y$. Margalit translates the lines: 'El sits in Ashtaroth, El rules in Edrei,' and attempts to substantiate his translation in terms of philology and syntax. Then he notes the reference to $\mathrm{Og}$, king of Bashan, in Joshua 12:4, who is described as 'one of the last of the Rephaites, who reigned in Ashtaroth and Edrei.' But, as several scholars have noted, the translation of the Ugarit text in this fashion is far from certain, both in terms of syntax and probability. It is more probable that the words should be translated: 'El sat (enthroned) with Athtart, El judged with Had, the shepherd.'so Again, Margalit's proposal is possible, but in my judgment not probable, and it is a slender basis upon which to build a 'Bashan Hypothesis,' which in turn would provide a possible link for more ancient and proximate relationships between the ancestors of the Israelites and those of the citizens of Ugarit.

Thus, Margalit has identified a crucial problem and attempted to resolve it in an original and detailed fashion. And although my criticisms here do not do full justice to Margalit's arguments, I do not find the evidence compelling; neither Bashan nor Galilee appears to offer the missing links in time and space between Ugarit and Jerusalem. Nevertheless, it is possible that

49. B. Margulis (Margalit), 'A Ugaritic Psalm (RS 24.252),' JBL 89 (1979) 292-304.

50. See Ugaritica 5, 553; S. B. Parker, 'The Feast of Rāpi'u,' UF 2 (1970) 243-49; C. E. L'Heureux, Rank Among the Canaanite Gods. El, Ba'al and the Rephaim (Missoula: Scholars Press, 1979) 169-73. While it is true that bhdr'y is written as one word, without the divider, nevertheless to interpret it as bhd $r^{\prime} y$ ('with Had, the Shepherd') is possible; the two previous words in the line are also written together, without a word divider. For arguments in support of the construction $y \underline{t b}$ plus $b$, see further $M$. Dahood, 'Ugaritic-Phoenician Forms in Job 34, 36,' Bib 62 (1981) 548-50. The same expression may perhaps be restored in RS. 24.245 .1 . 
with further evidence and further arguments, Margalit's hypotheses might gain in conviction.

\section{SOME CONCLUSIONS}

Let me first summarize some of the perspectives which are pertinent to comparative studies of Ugarit, Canaan, and Israel.

The following factors can be placed on the positive side, supporting the possibility of comparative studies that presuppose some form of historical interconnection.

(i) There were direct historical interconnections between Ugarit and Canaan; these contacts may also have formed the basis for cultural interaction and influence. In whichever direction such influence was at work, it is thus possible that the civilization known from the evidence of ancient Ugarit may be in certain ways similar to that of Canaan. Thus, in some Hebrew-Ugaritic studies, the similarities that are adduced may be interpreted as essentially Hebrew-Canaanite parallels. (ii) The dispersal of the Hurrians throughout both regions may also be interpreted as a positive factor. The presence of Hurrians in both Ugarit and Canaan as known from archaeological data, and the references to Hurrians in the old Testament, might suggest a further avenue for explaining comparative HebrewUgaritic data. Some examples of Hebrew-Ugaritic comparisons might be more precisely Hebrew-Hurrian parallels. In other cases, Ugaritic and/or Hebrew civilization may already have been influenced by the Hurrians, in such a fashion that the parallels are to be explained as secondary developments in one or both traditions. (iii) For all the differences between Ugarit and Canaan, the similarities should not be ignored. There clearly was some degree of commonality with respect to language, religion, and related matters; this general foundation of Ugaritic-Canaanite commonality may provide a further basis for interpreting Hebrew-Ugaritic parallels. This third point, however, is the perspective most commonly assumed in Hebrew-Ugaritic comparative studies, and the conviction with which it is held must be modified in the light of the negative factors which follow.

The negative factors, making more difficult the conduct of comparative studies, include the following points. It can not be assumed that Ugaritic civilization and culture were simply a branch of Canaanite civilization and culture. Granted that there were similarities between the 
two, the differences of language, literature, religion and culture in general were not insignificant. (ii) The differences in the nature and usage of the Ugaritic script in Ugarit as such and in various Canaanite centres indicate that in the matters of language and writing different forces and influences were at work in the north and south. Similar variations are evident in such matters as pottery, and peculiarities in local manifestations of religious cults. An awareness of these differences should indicate the danger of assuming that Ugarit and Canaan were simply part of the same cultural grouping, in the pursuit of comparative Hebrew-Ugarit studies. (iii) The geographical distance between northern Ugarit and southern Canaan/ Israel remains a difficulty for comparative studies. Geographical hypotheses attempting to bridge the gap between Ugarit and Jerusalem have not yet been entirely successfui. (iv) The problems of chronology remain in Ugaritic-Hebrew studies. Not only did the two kingdoms not exist concurrently, but neither are there explicit references to either state/people in the literary sources of the other. (There was a degree of overlap between the late Ugaritic kingdom and the early period of the Judges, if one works within a conventional chronological framework; the early Hebrew sources, though, do not mention Ugarit, and vice-versa.)

Thus a provisional conclusion (given the limited nature of the evidence) might be presented as follows. There are sufficient historical links and general similarities between Ugarit and Canaan to provide a general context for the interpretation of Hebrew-Ugaritic parallels. On the other hand, there are sufficient differences between Ugarit and Canaan, and sufficient regional peculiarities in each area, that no comparative work can be done without caution. I cannot agree with a statement made some years ago by $H$. L. Ginsberg that 'the Hebrew Bible and the Ugaritic texts are to be regareded as one literature, and consequently a reading in either one may be emended with the help of a parallel passage in the other. 51 Though that statement was made in 1943 and would no longer be

51. 'The Ugaritic Texts and Textual Criticism,' JBL 62 (1943) 109. 
espoused by many scholars, it remains an accurate description of much of the work of scholars like Mitchell Dahood. The great contributions which Dahood and others are continuing to make to old Testament studies must continue to be subject to rigorous scrutiny. There remain too many differences and difficulties between Ugarit, Canaan, and Israel, to assume that the evidence of all three may be perceived as belonging to a single linguistic and literary continuum. 